\title{
Correlation of photobleaching, oxidation and metal induced fluorescence quenching of DNA- templated silver nanoclusters
}

Kiyoshi Morishita, ${ }^{a}$ James L. MacLean, ${ }^{a}$ Biwu Liu, ${ }^{a}$ Hui Jiang,,${ }^{a, b}$ and Juewen Liu ${ }^{a^{*}}$

${ }^{a}$ Department of Chemistry and Waterloo Institute for Nanotechnology, University of Waterloo, 200 University Avenue West, Waterloo, Ontario, Canada N2L 3G1. Email: liujw@uwaterloo.ca

${ }^{b}$ State Key Laboratory of Bioelectronics (Chien-Shiung Wu Laboratory), Southeast University, Nanjing 210096, China

\begin{abstract}
Few atom noble metal nanoclusters have attracted a lot of interest due to their potential applications in biosensor development, imaging and catalysis. DNA-templated silver nanoclusters (AgNCs) are of particular interest as different emission colors can be obtained by changing the DNA sequence. A popular analytical application is fluorescence quenching by $\mathrm{Hg}^{2+}$, where $d^{10}-d^{10}$ metallophilic interaction has often been proposed for associating $\mathrm{Hg}^{2+}$ with nanoclusters. However, it cannot explain the lack of response to other $d^{10}$ ions such as $\mathrm{Zn}^{2+}$ and $\mathrm{Cd}^{2+}$. In our effort to elucidate the quenching mechanism, we studied a total of eight AgNCs prepared by different hairpin DNA sequences; they showed different sensitivity to $\mathrm{Hg}^{2+}$ and DNA with a larger cytosine loop size produced more sensitive AgNCs. In all the cases, samples strongly quenched by $\mathrm{Hg}^{2+}$ were also more easily photobleached. Light of shorter wavelengths bleached AgNCs more potently, and photobleached samples can be recovered by $\mathrm{NaBH}_{4}$. Strong fluorescence quenching was also observed with high redox potential metal ions such as $\mathrm{Ag}^{+}, \mathrm{Au}^{3+}, \mathrm{Cu}^{2+}$ and $\mathrm{Hg}^{2+}$, but not with low redox potential ions. Such metal induced quenching cannot be recovered by $\mathrm{NaBH}_{4}$. Electronic absorption and mass spectrometry studies offered further insights into the oxidation reaction. Our results correlate many important experimental observations and will fuel the further growth of this field.
\end{abstract}




\section{Introduction}

Few-atom noble metal nanoclusters (NCs) have emerged as a class of promising materials for biosensor development, imaging and catalysis. ${ }^{1-6}$ Unlike metal nanoparticles, NCs possess well-defined structures and discrete electronic energy bands that allow radiative relaxation to produce fluorescence with a high quantum yield. ${ }^{7}$ Compared to semiconductor quantum dots, ${ }^{8}$ gold and silver NCs have fewer toxicity concerns. As a bridge between traditional organometallic chemistry and nanoparticle science, NCs are important for fundamental studies. Most NCs are prepared by reducing metal salts. To prevent a rapid growth into nanoparticles, such reduction reactions are often carried out in the presence of a polymeric ligand (e.g. proteins, DNA, or synthetic polymers). ${ }^{2,7,9-17}$ Cytosine-rich DNAs bind to $\mathrm{Ag}^{+}$strongly, ${ }^{9,18}$ and many DNA-stabilized AgNCs with various emission colors have been prepared by changing the DNA sequence. ${ }^{19-23}$ On the practical side, by rational incorporation of DNA aptamers, the fluorescence signaling of AgNCs has been successfully coupled with the molecular recognition property of DNA to design biosensors and smart imaging probes. ${ }^{24-36}$

An interesting and useful discovery is that the fluorescence of many NCs is strongly quenched by $\mathrm{Hg}^{2+}$, allowing its detection at low $\mathrm{nM}$ and even sub-nM concentrations. ${ }^{20,37-42}$ Despite its importance in analytical chemistry, our fundamental understanding of NCs is still quite limited. For example, $\mathrm{Hg}^{2+}$-induced quenching has often been attributed to the $d^{10}-d^{10}$ metallophilic interactions with $\mathrm{Au}^{+}$or $\mathrm{Ag}^{+}$that may be present in $\mathrm{NCs} .{ }^{37,43}$ However, $\mathrm{Zn}^{2+}$ and $\mathrm{Cd}^{2+}$ do not induce $\mathrm{NC}$ fluorescence quenching, even though they also possess the $d^{10}$ electronic structure. In addition, we noticed that most $\mathrm{AgNCs}$ used for $\mathrm{Hg}^{2+}$ detection emit red fluorescence, but it is unclear whether different NCs have the same sensitivity to $\mathrm{Hg}^{2+}$ or not. Furthermore, some AgNCs are susceptible to oxidation. Dickson and co-workers showed that oxidized NCs have a completely different fluorescence property. ${ }^{44}$ Several groups have also reported the conversion of AgNCs with different emission colors through an oxidation reaction. ${ }^{44-46}$ In some cases, oxygen was identified as a requirement to produce fluorescent AgNCs; in an oxygen-free condition, only non-fluorescent species was produced. ${ }^{47}$ Finally, 
many AgNCs have relatively low photostability. ${ }^{44,48,49}$ In this work, we take the advantage that AgNCs of different emission colors can be produced using different DNA sequences and prepared a total of eight AgNCs. We show that AgNCs have different sensitivity to $\mathrm{Hg}^{2+}$ and different photostability. Instead of the $d^{10}-d^{10}$ metallophilic interaction, we propose that redox reaction is the main force driving metal ions to interact with AgNCs. This work unifies oxidation, photobleaching and $\mathrm{Hg}^{2+}$ sensitivity to the redox property of AgNCs.

\section{Materials and Methods}

Chemicals. All of the DNA samples were purchased from Integrated DNA Technologies (IDT, Coralville, IA) and purified by standard desalting. $\mathrm{AgNO}_{3}, \mathrm{NaBH}_{4}, \mathrm{Hg}\left(\mathrm{ClO}_{4}\right)_{2}, \mathrm{HAuCl}_{4}, \mathrm{CuSO}_{4}, \mathrm{MnCl}_{2}$, $\mathrm{CoCl}_{2}, \mathrm{NiSO}_{4}, \mathrm{ZnCl}_{2}, \mathrm{~Pb}(\mathrm{OAc})_{2}$, and $\mathrm{Cd}\left(\mathrm{NO}_{3}\right)_{2}$ were from Sigma-Aldrich. 4-(2-hydroxyethyl)-1piperazineethanesulfonic acid (HEPES) and its sodium salt were purchased from Mandel Scientific (Guelph, ON). Milli-Q water was used for making buffers and dilutions.

AgNC preparation. For fluorescence measurements, each sample contained $15 \mu$ M DNA and $120 \mu$ M $\mathrm{AgNO}_{3}$ dissolved in $25 \mathrm{mM}$ HEPES buffer ( $\mathrm{pH}$ 7.6) with $270 \mu \mathrm{M} \mathrm{NaBH}$ as the reducing agent. $\mathrm{NaBH}_{4}$ was freshly prepared right before its addition. After addition of $\mathrm{NaBH}_{4}$, the sample was rapidly mixed and stored in the dark for overnight reaction. Alternatively, if $120 \mu \mathrm{M} \mathrm{NaBH} 4 \mathrm{was}$ used, the incubation was $\sim 2 \mathrm{hr}$.

Fluorescence spectroscopy. AgNCs from the above preparation $(30 \mu \mathrm{L})$ were dissolved in $570 \mu \mathrm{L} 10$ $\mathrm{mM}$ HEPES buffer ( $\mathrm{pH}$ 7.6). The excitation peak in the visible region was determined first and then the emission peaks were scanned at the excitation maximum. All fluorescence spectra were collected using a Varian Eclipse fluorometer at room temperature.

Light and $\mathbf{H g}^{2+}$ sensitivity. For light sensitivity, the fluorescence spectra were collected before and after $5,10,15,20,25$ and $30 \mathrm{~min}$ exposure to a fluorescent tube light. For $\mathrm{Hg}^{2+}$ sensitivity, fluorescence spectra of the samples were collected at 0, 10, 20, 30, 50, 70, 100, 150 and $200 \mathrm{nM} \mathrm{Hg}^{2+}$. 
A few microliters of 5 or $20 \mu \mathrm{M} \mathrm{Hg}{ }^{2+}$ solutions were added to achieve the designated $\mathrm{Hg}^{2+}$ concentration. To test the sensitivity of AgNCs to other metal ions, solutions of the metal salts were prepared and fluorescence spectra were collected at 0, 200 and $2000 \mathrm{nM}$ metal ion concentrations. All the reactions were carried out in $10 \mathrm{mM}$ HEPES buffer ( $\mathrm{pH}$ 7.6). The slopes of $\mathrm{Hg}^{2+}$ from 0 to $100 \mathrm{nM}$ and light exposure from 0 to 5 min were used for calculating sensitivity.

Fluorescence recovery using $\mathbf{N a B H}_{4}$. After an initial scan, the samples were exposed to $200 \mathrm{nM} \mathrm{Hg}^{2+}$ or 30 min continuous fluorescent tube light. The emission spectrum was collected again, and then $1 \mu \mathrm{L}$ of $2 \mathrm{mM} \mathrm{NaBH}_{4}$ was added to the samples. The samples were moved to the dark for one hour to allow for fluorescence recovery. They were then scanned once more to check for fluorescence recovery. This procedure of $\mathrm{Hg}^{2+} /$ light exposure and addition of $\mathrm{NaBH}_{4}$ was repeated two more times. A fluorescence spectrum was collected after each step, yielding a total of 7 measurements for each sample.

Light wavelength sensitivity. Fluorescence spectra were obtained after 0, 2, 5, 10 and 15 min light exposure from the lamp in our fluorometer. The wavelength of exposure light was fixed by the fluorometer (slit width $=10 \mathrm{~nm}$ ). The wavelengths tested were 225, 250, 275, 300, 400, 436, $557 \mathrm{~nm}$ (DNA1) and 225, 250, 275, 300, 350, $466 \mathrm{~nm}$ (DNA4).

Mass spectrometry. Samples containing $150 \mu \mathrm{M}$ DNA1, $1.2 \mathrm{mM} \mathrm{AgNO} 3$ and $1.35 \mathrm{mM} \mathrm{NaBH}_{4} \mathrm{were}^{-2}$ dissolved in water without additional buffer. After vigorous mixing and overnight reaction in the dark, mercury was added, yielding an $\mathrm{Hg}^{2+}$ concentration of $40 \mu \mathrm{M}$. The sample without light or $\mathrm{Hg}^{2+}$ exposure was added with a small amount of $\mathrm{NaBH}_{4}$ right before the measurement to eliminate oxidized AgNCs. The samples were centrifuged and the supernatant was removed and mixed with water:acetonitrile $(1: 1)$ containing $0.5 \% \mathrm{NH}_{4} \mathrm{OH}$ to facilitate ionization. Mass spectra were obtained using a Micromass Q-TOF Ultima Global mass spectrometer using electrospray ionization (ESI).

UV-vis spectroscopy. The electronic absorption of AgNCs was monitored using a UV-vis spectrophotometer (Agilent 8453A). The samples for UV-vis were prepared the same way as that in the 
mass spectrometry studies. The final DNA concentration in the cuvette was $30 \mu \mathrm{M}$ and the $\mathrm{Hg}^{2+}$ concentration was $20 \mu \mathrm{M}$. The samples were dissolved in water without additional salt or buffer.
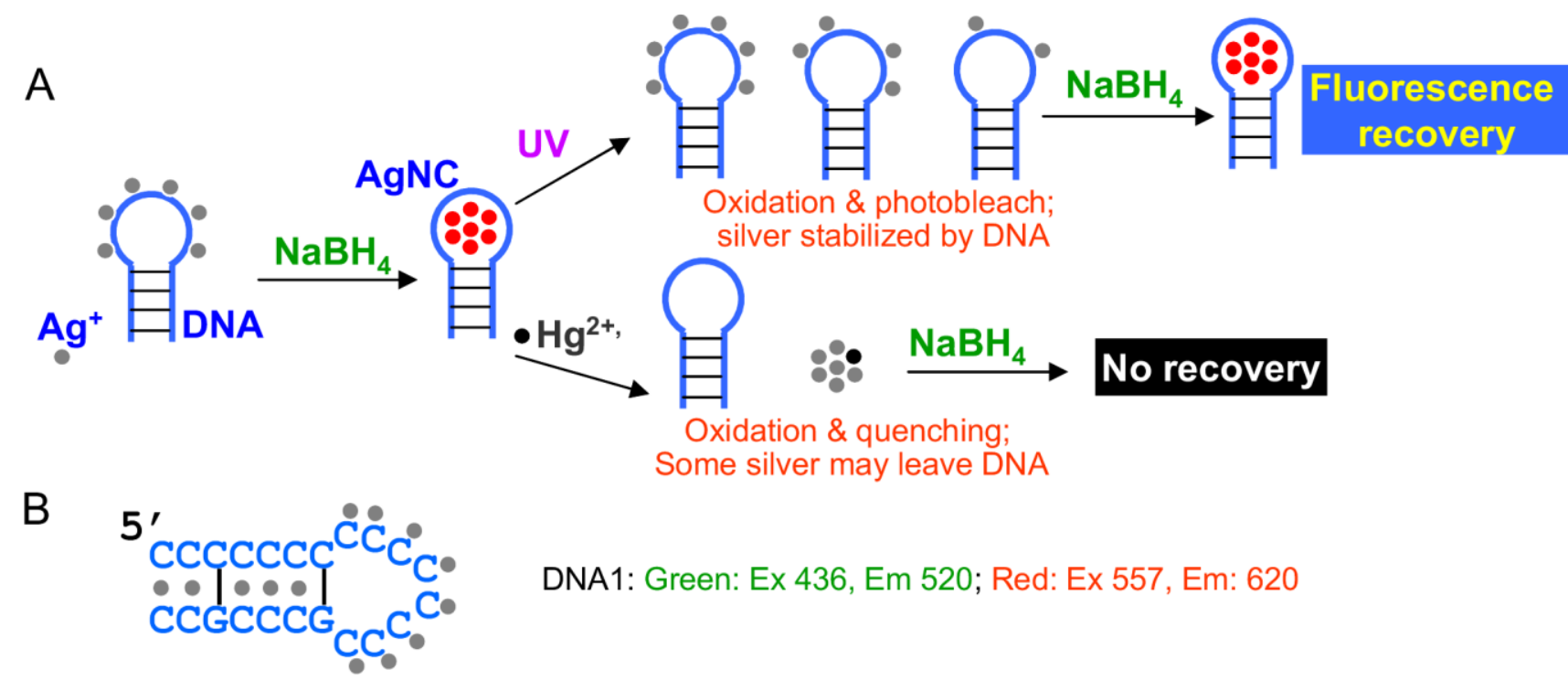

DNA1: Green: Ex 436, Em 520; Red: Ex 557, Em: 620

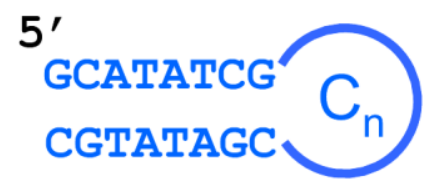

DNA2 (n=5): Green: Ex 466, Em 552; Red: Ex 555, Em: 649 DNA3 (n=8): Green: Ex 450, Em 550; Red: Ex 530, Em: 630 DNA4 (n=11): Ex 564, Em: 630 DNA5 (n=14): Ex 570, Em: 635

Figure 1. (A) Schematics of DNA templated synthesis of a fluorescent AgNC and its reaction with UV light, metal ions of high and low oxidation power. The gray dots are $\mathrm{Ag}^{+}$ions and red dots are silver in fluorescent AgNCs. Note that the sensitivity to $\mathrm{UV}$ and to $\mathrm{Hg}^{2+}$ is correlated through oxidative reactions but through different reaction mechanisms. UV-induced quenching can be recovered by adding $\mathrm{NaBH}_{4}$, but $\mathrm{Hg}^{2+}$-induced AgNC quenching cannot be recovered since the AgNC may dissociate from the DNA. (B) DNA sequences used in this study and the excitation and emission wavelength of AgNCs produced by these DNA. Some DNAs produce dual emitters.

\section{Results and Discussion}

Correlation between light and $\mathbf{H g}^{2+}$ exposure. Using a cytosine-rich DNA that can fold into a hairpin in the presence of $\mathrm{Ag}^{+}$(DNA1, see Figure 1B for DNA sequence), we prepared a dual emitting AgNC sample with both red and green fluorescence peaks. Such hairpin-stabilized dual emitters have also been reported by using other DNA sequences. ${ }^{45}$ As shown in Figure $2 \mathrm{~A}$, the red peak was almost completely quenched by $200 \mathrm{nM} \mathrm{Hg}^{2+}$, whereas the green peak increased slightly in the same process. 
Since these two AgNCs were tested in the same tube, we can conclude that the red emitter is much more sensitive to $\mathrm{Hg}^{2+}$ than the green emitter. Some of the red emitters might even be converted to the green emitter by $\mathrm{Hg}^{2+}$. This is the first report that $\mathrm{AgNCs}$ have different sensitivity to $\mathrm{Hg}^{2+}$. In this case, the green and red peaks were respectively excited at $436 \mathrm{~nm}$ and $557 \mathrm{~nm}$ to achieve a high quantum yield for their emissions at 520 and $620 \mathrm{~nm}$. To monitor both emission peaks at the same time, excitation at $230 \mathrm{~nm}$ was also employed. Although $260 \mathrm{~nm}$ is likely to provide a more efficient excitation via DNA base absorption, ${ }^{50}$ we refrained from choosing $260 \mathrm{~nm}$ to avoid a double frequency artifact that masks the $520 \mathrm{~nm}$ emission peak. As shown in Figure 2B (black spectrum), both peaks were excited simultaneously with a comparable initial emission intensity. As more fluorescence scanning was performed, the green peak increased while the red peak dropped even in the absence of $\mathrm{Hg}^{2+}$. After 9 scans with each scan taking $3 \mathrm{~min}$, the red peak dropped $\sim 80 \%$. The presence of an isosbestic point at $560 \mathrm{~nm}$ is a strong indication of the conversion between the two emitters. Since UV light exposure produced similar results to the addition of $\mathrm{Hg}^{2+}$ (e.g. increased green and decreased red), we want to test whether there is such a correlation for other AgNCs. It needs to be pointed out that light induced production of green fluorescence appears to be more efficient than that induced by $\mathrm{Hg}^{2+}$. Therefore, the exact chemical process might not be the same for these two stimuli but they may share the same origin.
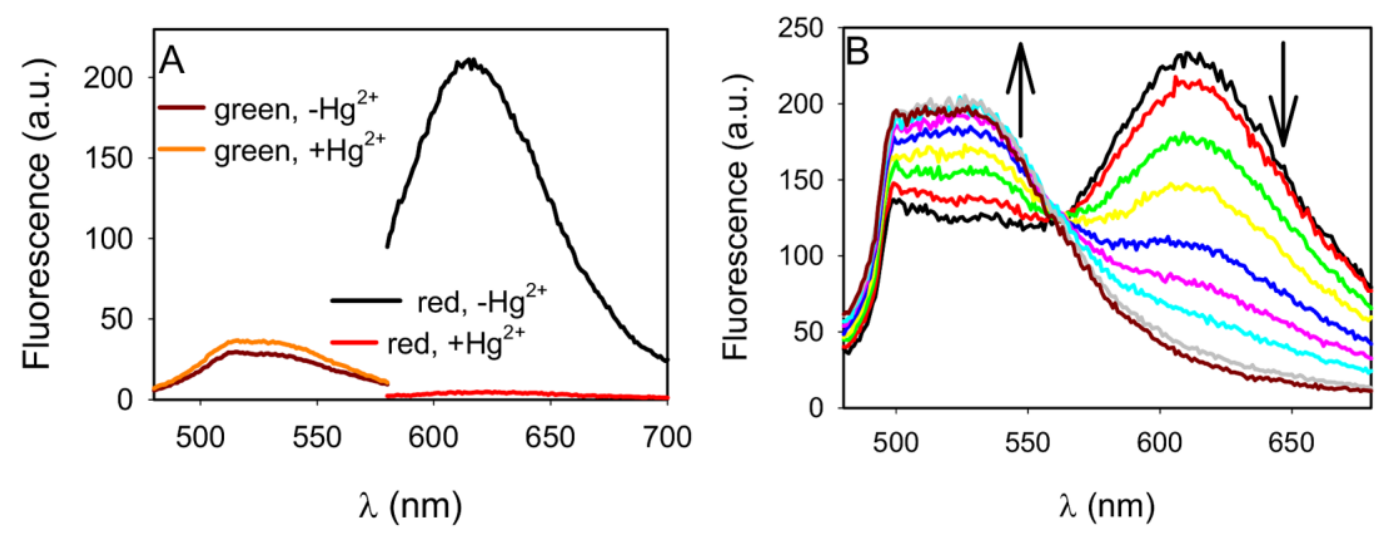
Figure 2. (A) Fluorescence spectra of AgNCs templated by DNA1 before and after adding $200 \mathrm{nM}$ $\mathrm{Hg}^{2+}$. There are two emitters in this sample and the excitation wavelengths are in Figure 1B. The green emitter is enhanced slightly by $\mathrm{Hg}^{2+}$ and the red emitter is quenched. (B) Fluorescence spectra of AgNCs templated by DNA1 excited at $230 \mathrm{~nm}$. A total of 9 scans were measured, each taking $\sim 3$ min. The initial spectrum is in black. The $620 \mathrm{~nm}$ emission peak intensity is decreased while the $520 \mathrm{~nm}$ peak is increased as the number of scans is increased. $\mathrm{No}^{2+}$ was added to this sample.

To test whether there is a general correlation between light and $\mathrm{Hg}^{2+}$ sensitivity, we employed four additional DNA hairpins (DNA2-5, see Figure 1B) with various sized poly-cytosine loops. DNA2 and 3 also produced dual emitters with both green and red emissions, while only red fluorescence was observed with DNA4 and 5. Since three of the DNAs produced dual emitters, a total of eight emitters were measured. For each emitter, the excitation maximum in the visible region was used to collect the fluorescence spectrum, since UV excitation might change its fluorescence properties during the measurement. The light sensitivity was obtained by exposing the samples to a fluorescent tube lamp at 5 min intervals. The fluorescence spectra of a light sensitive sample templated by DNA4 are presented in Figure 3A. Within $30 \mathrm{~min}$, the fluorescence was quenched by $\sim 80 \%$. For the $\mathrm{Hg}^{2+}$ sensitivity test, the sample was challenged with up to $200 \mathrm{nM} \mathrm{Hg}^{2+}$ and its fluorescence was quenched by $~ 90 \%$ (Figure 3B). The same procedure was repeated for all the other AgNCs.

It is particularly interesting to compare DNA2-5 since they produced a similar red emission color but were stabilized by DNA hairpins of different sizes. The AgNCs templated by DNA2 (e.g. 5cytosine loop) were quenched only $\sim 20 \%$ by $\mathrm{Hg}^{2+}$ and were also the least sensitive to light exposure (Figure 3C, D, black dots). For DNA4 and 5 with 11 and 14 cytosines, respectively, the majority of the fluorescence was quenched by light and $\mathrm{Hg}^{2+}$. Therefore, as the hairpin loop size was increased, both light and $\mathrm{Hg}^{2+}$ sensitivity of the red emitters increased. The sensitivities of the green emitters from DNA2 and DNA3 as well as the two emitters from DNA1 are presented in Figure 3E, F. The green emitter from DNA1 was increased by both light and $\mathrm{Hg}^{2+}$, while the red emitter was almost completely 
quenched. If the sample is stored in dark, the decrease of fluorescence is $\sim 1 \%$ every 30 min (Figure S1, ESI). ${ }^{48}$
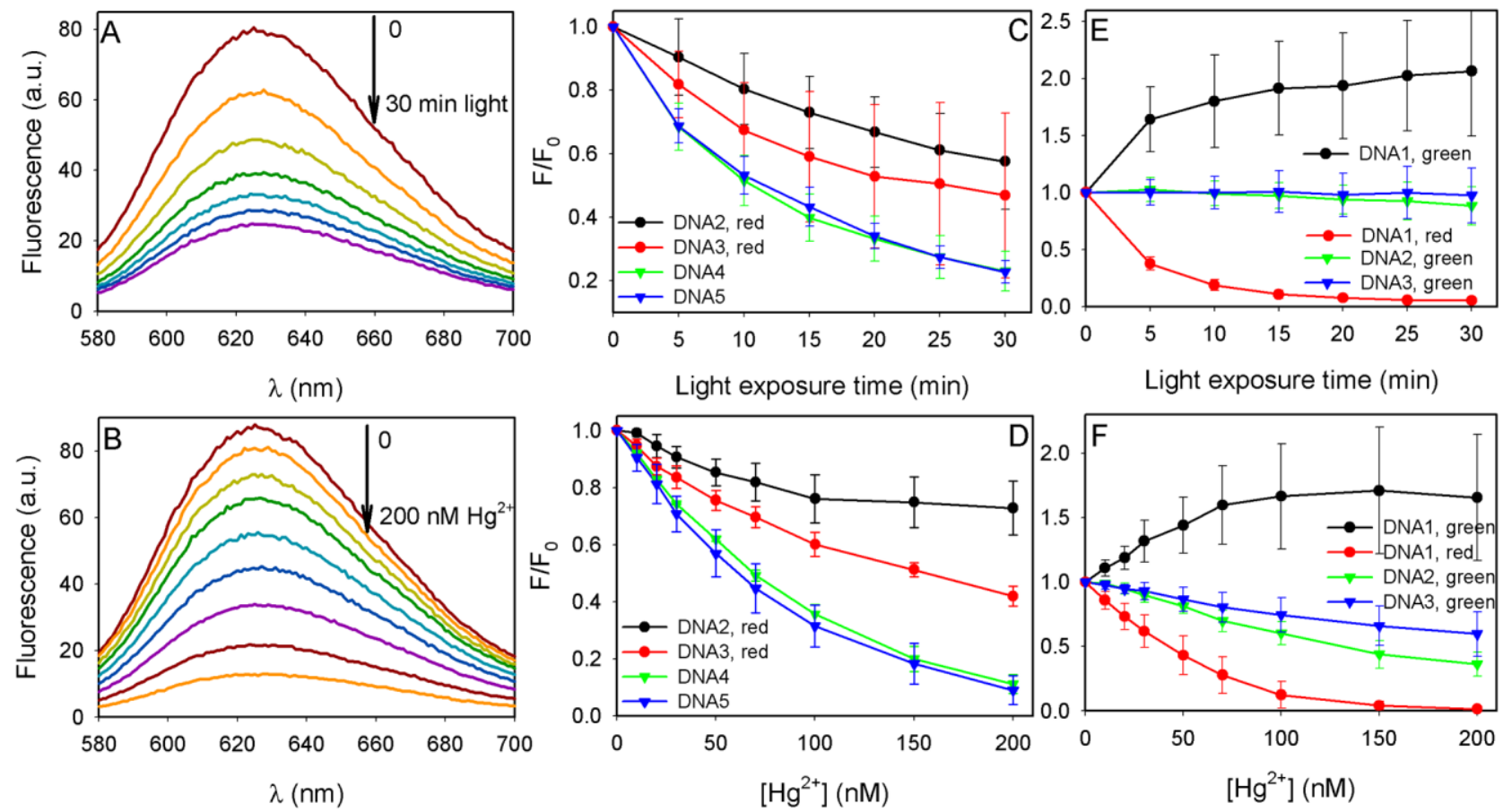

Figure 3. Fluorescence spectra of AgNCs templated by DNA4 with light (A) or $\mathrm{Hg}^{2+}$ exposure (B). Fluorescence sensitivity to $\mathrm{Hg}^{2+}(\mathrm{D}, \mathrm{F})$ and light $(\mathrm{C}, \mathrm{E})$ of various AgNCs.

Since the initial quenching induced by $\mathrm{Hg}^{2+}$ appeared to be linear for most samples, we used the initial slope (e.g. $\mathrm{Hg}^{2+}$ concentration from 0 to $100 \mathrm{nM}$ ) to quantify $\mathrm{Hg}^{2+}$ sensitivity. For light sensitivity, the initial linear part was also calculated. The relationship between $\mathrm{Hg}^{2+}$ and light sensitivity is plotted in Figure 4. A linear relationship was observed for all tested AgNCs with an $R^{2}$ value of 0.971 . The green emitter templated by DNA1 was the only one that showed a significant increase in fluorescence and thus positive sensitivity for both light and $\mathrm{Hg}^{2+}$ exposure. This linear correlation strongly suggests that $\mathrm{Hg}^{2+}$ binding and light sensitivity may share the same origin (note that the reactions themselves are likely to be different). This study also indicates that DNA sequence 
plays a crucial role in affecting the interaction between $\mathrm{AgNCs}$ and $\mathrm{Hg}^{2+}$ or light. It is likely that a smaller hairpin allows tighter binding of AgNCs, blocking its interaction with $\mathrm{Hg}^{2+}$.

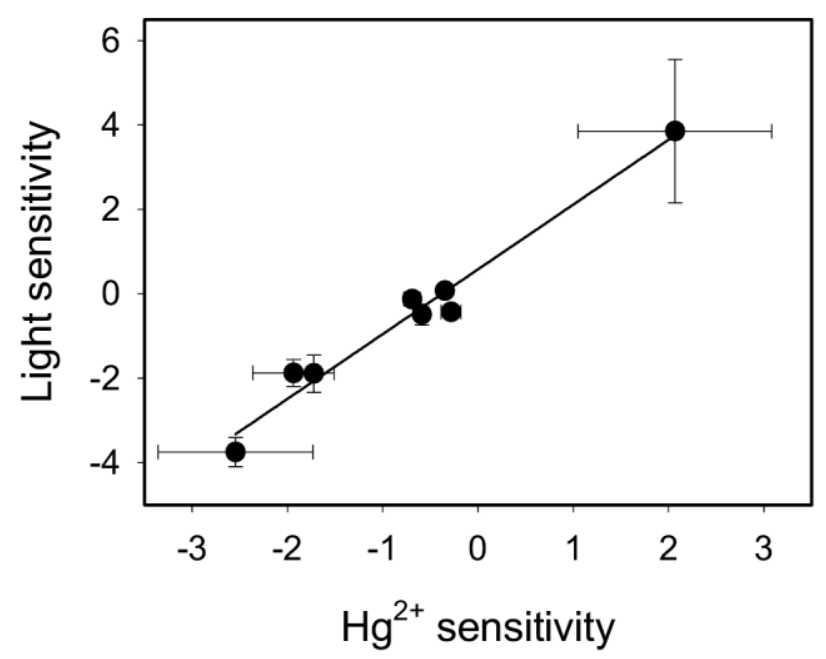

Figure 4. Correlation between $\mathrm{Hg}^{2+}$ sensitivity and light sensitivity of the AgNCs prepared in this study.

Sensitivity to the wavelength of light. Since the fluorescent tube light contains a broad range of wavelengths, to systematically test the wavelength dependency of photobleaching, we exposed AgNCs templated by DNA1 and 4 to selected wavelengths from the fluorometer lamp. DNA1 was chosen to represent dual emitters and it showed an interesting red-to-green conversion. DNA4 was chosen because it produced a highly fluorescent red emitter (quantum yield $=\sim 45 \%$ using Rhodamine-B as standard). For the emitter by DNA4, the strongest bleaching occurred with the shortest $225 \mathrm{~nm}$ exposure (Figure 5A). No bleaching was observed with wavelengths longer than $300 \mathrm{~nm}$. Even with its direct excitation wavelength of $566 \mathrm{~nm}$ exposure, little photobleaching occurred. Similar observations were also made for AgNCs templated by DNA1, which produced dual emitters (Figure 5B). The green emitter intensity increased and the red was quenched upon UV light exposure. The change of intensity was again more drastic with shorter wavelength exposure. Exposure to its direct excitation wavelengths 
at 436 and $557 \mathrm{~nm}$ also failed to induce emission change (data not shown). Therefore, the energy of incoming light is critical for the photobleaching of AgNCs. DNA-templated AgNCs can be excited either via DNA base absorption and subsequent energy transfer or directly via visible light. ${ }^{50}$ Since 225 $\mathrm{nm}$ exposure showed a stronger bleaching effect than $250 \mathrm{~nm}$ exposure, photobleaching should not occur via DNA base absorption (e.g. DNA bases absorb at $260 \mathrm{~nm}$ ). To minimize photobleaching, it is thus better to excite AgNCs in the visible region for fluorescence spectral measurements. Short wavelength UV light generates reactive oxygen species with strong oxidation power. ${ }^{51}$ Therefore, oxidation might be the ultimate reason for the photobleaching of AgNCs.
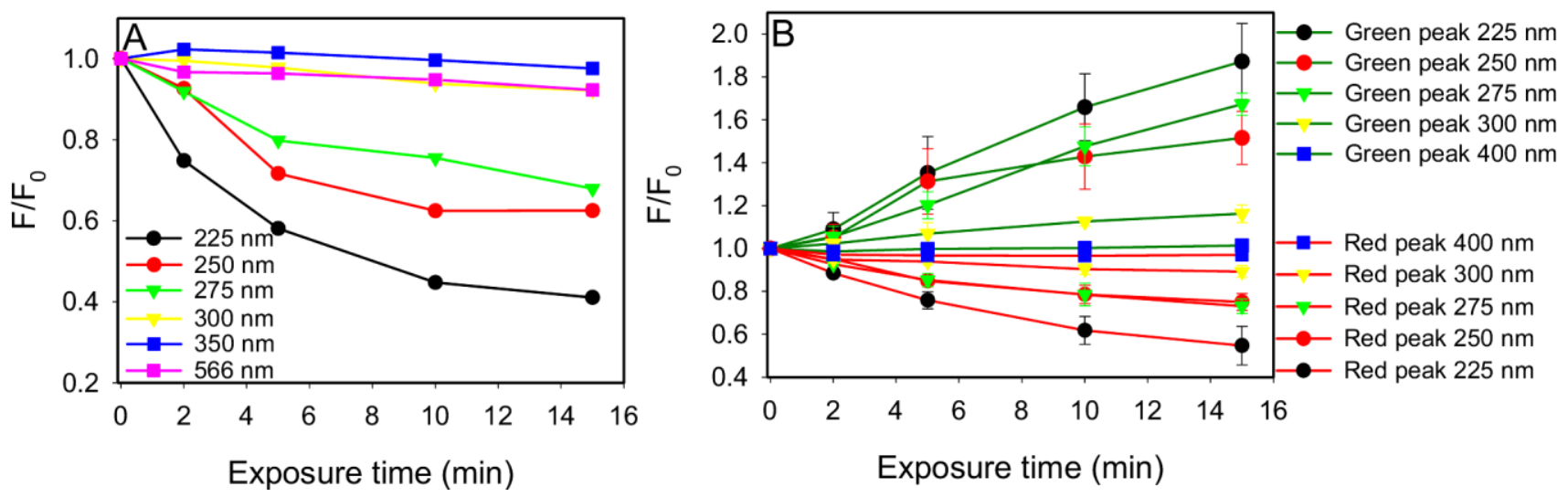

Figure 5. Relative fluorescence change of AgNCs templated by DNA4 (A) and DNA1 (B) after exposure to light at designated wavelengths over time. DNA1 produced two emitters, where the green emitter is enhanced by light exposure.

Photobleaching and oxidation. Excited fluorophores have higher energy and more easily react with molecules such as oxygen to generate non-fluorescent species. Such light-induced fluorescence decrease is called photobleaching, which is usually an irreversible process for organic fluorophores. We observed that UV light can achieve the conversion between the red and green emitters templated by DNA1 (Figure 2). In addition, shorter wavelengths are more effective for the bleaching reaction. 
Therefore, we postulate that the effect of light on AgNCs is to induce oxidation. We first tested this hypothesis using AgNCs templated by DNA4. After measuring its initial fluorescence intensity, the sample was exposed to light for $30 \mathrm{~min}$, which quenched its fluorescence (Figure 6A). Addition of a reducing agent $\left(\mathrm{NaBH}_{4}\right)$ resulted in fluorescence exceeding the original value, suggesting that the initial sample was already partially oxidized. This process can be repeatedly performed, suggesting that photobleaching is a reversible oxidation reaction. DNA1 produced dual emitters and we also studied this sample (Figure 6B). There is an anti-correlation between the red and green emitters. The green fluorescence increased upon light exposure but decreased upon $\mathrm{NaBH}_{4}$ treatment, suggesting that it is the oxidized species while the red emitter is the reduced species. This bleaching and recovery operation can also be carried out for many cycles. Using these two examples, we reason that light-induced bleaching is through oxidation of AgNCs. The oxidation product can be non-fluorescent (e.g. DNA4) or a different fluorescent cluster in the case of DNA1. 

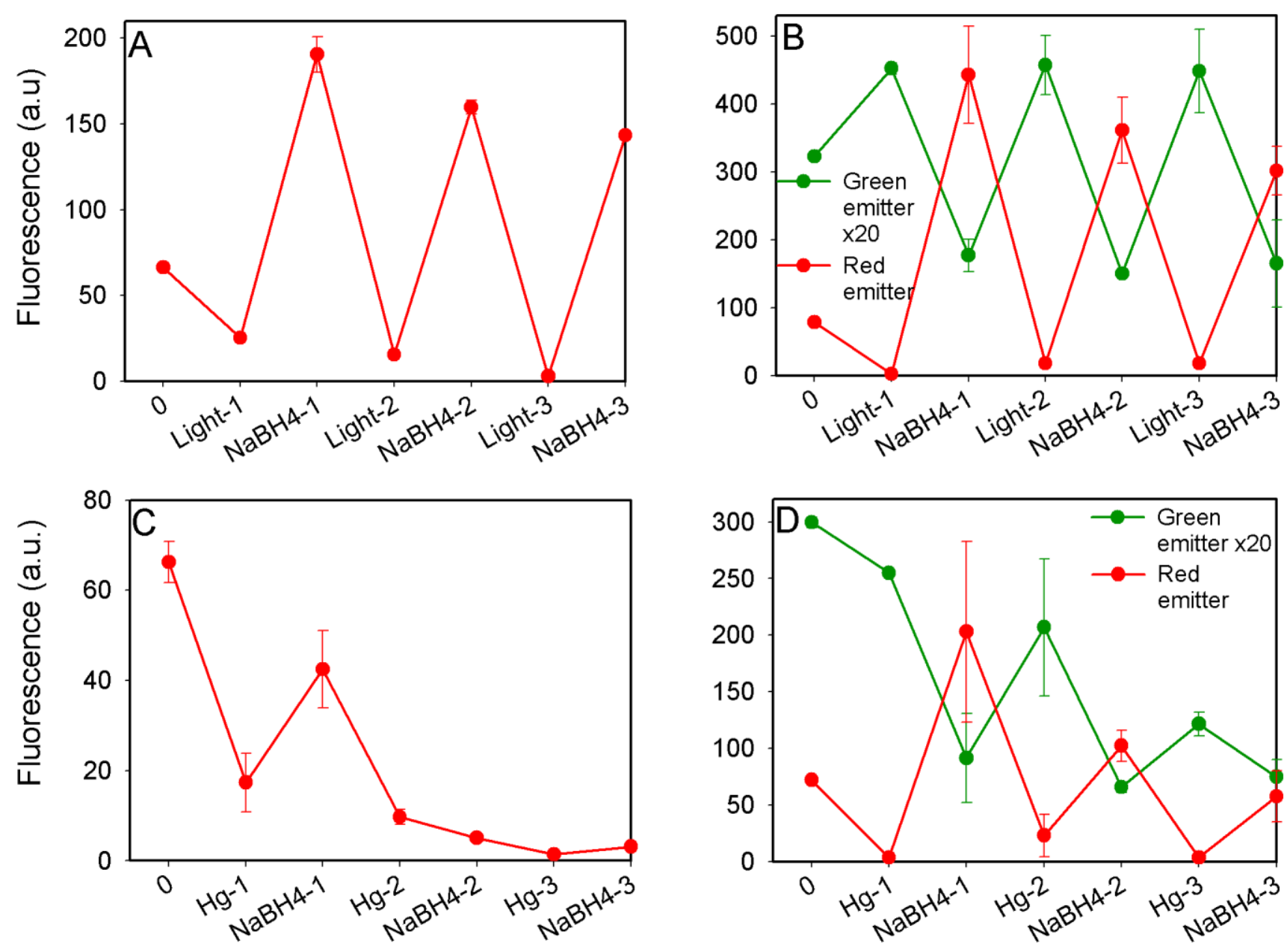

Figure 6. Fluorescence recovery of $\mathrm{AgNCs}$ by adding $\mathrm{NaBH}_{4}$ for samples templated by DNA4 after exposure to light (A) or to $200 \mathrm{nM} \mathrm{Hg}^{2+}$ (C) and for samples templated by DNA1 after exposure to light (B) or to $\mathrm{Hg}^{2+}$ (D). The light source is ambient fluorescent tube light.

Since a strong correlation between light and $\mathrm{Hg}^{2+}$ sensitivity has been shown in Figure 4, a related question is whether the $\mathrm{Hg}^{2+}$ treated samples can also be recovered by adding $\mathrm{NaBH}_{4}$. Ying and co-workers showed partially fluorescence recovered of BSA stabilized AuNCs quenched by $\mathrm{Hg}^{2+} \cdot 37$ However, only one regeneration step was demonstrated in that study. For our AgNCs templated by DNA1, red fluorescence recovery and the anti-correlation between red and green were observed (Figure 6D). In addition, multiple regeneration cycles were also achieved. Compared to the light exposure/recovery in Figure 6B, however, the fluorescence intensities decayed significantly as the number of recovery cycles increased for the $\mathrm{Hg}^{2+}$ treated sample (e.g. $\sim 50 \%$ loss for each regeneration). 
Therefore, while the effect of $\mathrm{Hg}^{2+}$ is similar to that of light as an oxidation agent, $\mathrm{Hg}^{2+}$ also induced irreversible reactions. This irreversible component was even more pronounced for DNA4 (Figure 6C), where fluorescence decreased upon the first addition of $\mathrm{Hg}^{2+}$ and a slight recovery was achieved by the first addition of $\mathrm{NaBH}_{4}$. However, no subsequent recovery was observed by adding more $\mathrm{Hg}^{2+}$ and $\mathrm{NaBH}_{4}$. We attribute this initial recovery to the reducing of oxidized species (previously oxidized by air) by $\mathrm{NaBH}_{4}$, while $\mathrm{Hg}^{2+}$ induced quenching cannot be recovered by $\mathrm{NaBH}_{4}$. Once these regenerated emitters were also quenched by $\mathrm{Hg}^{2+}$ in its second addition, no more regeneration could take place. Bringing these results together, $\mathrm{Hg}^{2+}$ acts as an irreversible oxidizing agent while light induced oxidation is reversible. DNA1 stabilizes two emitters; the green emitter is less affected by $\mathrm{Hg}^{2+}$ and thus acts as a reservoir for the red emitter during the $\mathrm{NaBH}_{4}$ reaction. Addition of $\mathrm{Hg}^{2+}$ converts some of the red emitters back to green and the rest red emitters are irreversibly quenched. The percentage of the red emitters that undergo $\mathrm{Hg}^{2+}$ induced irreversible quenching or reversible conversion to green is comparable, leading to only $\sim 50 \%$ recovery for the red peak each time (Figure 6D). This is not the case for DNA4 since it has only one emitter. $\mathrm{Hg}^{2+}$ eliminates this emitter and it cannot be reversed by adding $\mathrm{NaBH}_{4}$. To ensure that fluorescence quenching upon light exposure is not related to DNA damage, we performed a control experiment by exposing DNA to light first followed by AgNC synthesis. In that case, we observed the same AgNC fluorescence intensity regardless of whether DNA was exposed to light (for $30 \mathrm{~min}$ ) or not (see Figure S2, ESI).

To further understand these reactions, the AgNCs were analyzed by UV-vis spectroscopy. AgNCs templated by DNA4 show two absorption peaks at $440 \mathrm{~nm}$ and $560 \mathrm{~nm}$ (Figure 7A, black curve). Note that the $560 \mathrm{~nm}$ peak matches the excitation wavelength of this AgNC. Addition of $\mathrm{Hg}^{2+}$ eliminated the light absorption at $560 \mathrm{~nm}$ (red curve), which is reflected by the color change (inset) and is the direct reason for fluorescence quenching. This indicates that the $560 \mathrm{~nm}$ (absorption) emitter is converted to other species that does not show absorption features in the visible region. Exposure of the same sample to light also eliminated the $560 \mathrm{~nm}$ peak but the $420 \mathrm{~nm}$ peak increased in the same 
process (green curve), indicating the conversion of the red emitter to non-fluorescent but still absorbing clusters. The $560 \mathrm{~nm}$ peak recovered after treating the sample with $\mathrm{NaBH}_{4}$ (Figure S3, ESI), confirming reversibility. For AgNCs templated by DNA1, two absorption peaks were again observed. In this case, both peaks produce fluorescence emissions. Addition of $\mathrm{Hg}^{2+}$ reduced the $500 \mathrm{~nm}$ peak more than the $400 \mathrm{~nm}$ peak, which is similar to that for DNA4. Light exposure only dropped the 500 $\mathrm{nm}$ peak while the $400 \mathrm{~nm}$ appeared to increase just slightly.

For both DNA samples, light exposure seems to convert the red emitters to other species that can still be detected by light absorption. $\mathrm{Hg}^{2+}$ exposure, on the other hand, seems to eliminate the red emitters without generating new species that can absorb in the visible region. This may explain the difference between light and $\mathrm{Hg}^{2+}$ exposure in terms of fluorescence recovery by adding $\mathrm{NaBH}_{4}$.
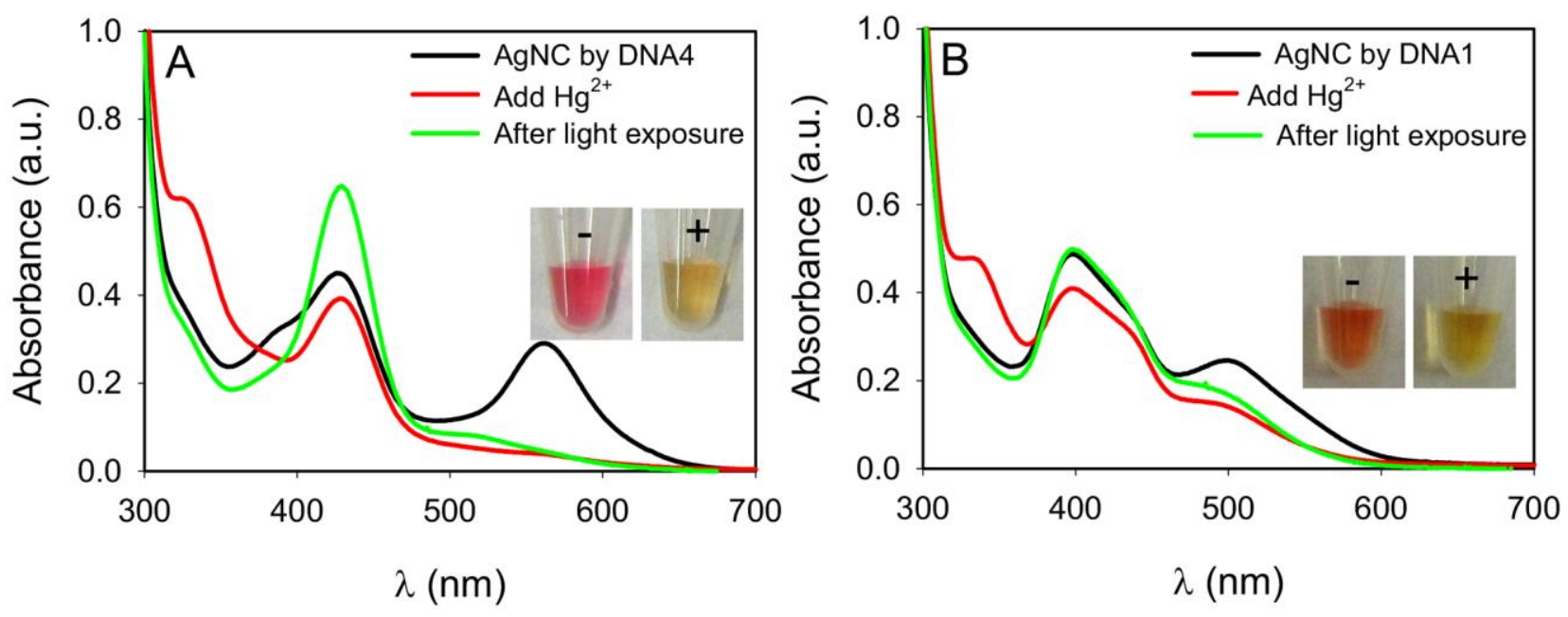

Figure 7. UV-vis spectra of AgNCs templated by DNA4 (A) and DNA1 (B) upon $\mathrm{Hg}^{2+}$ and light exposure. Insets: photographs of $\mathrm{AgNCs}$ in the absence and presence of $\mathrm{Hg}^{2+}$. The $\mathrm{Hg}^{2+}$ concentration is $40 \mu \mathrm{M}$ in the inset. 
To further understand the reaction mechanism, we followed the $\mathrm{Hg}^{2+}$ and light reaction using mass spectrometry. Figure 8A shows the mass distribution of the AgNCs templated by DNA1. It has a peak of free DNA1, the complex of DNA1:Ag 10 cluster as a major peak and also DNA1:Ag 13 . After $\mathrm{Hg}^{2+}$ addition, the color of the sample changed from brown to yellow but the speciation in the mass spectrum changed only slightly (Figure $8 \mathrm{C}$ ). The relative abundance of the $\mathrm{Ag}_{10}$ peak decreased by 50\%. Interestingly, the $\operatorname{Ag}_{13}$ peak disappeared while a new peak of $\operatorname{Ag}_{12}$ appeared. Since $\mathrm{Hg}^{2+}$ completely quenches the fluorescence of the sample, it is unlikely that $\mathrm{Ag}_{10}$ is the fluorescent species. We assigned $\mathrm{Ag}_{13}$ to be the red emitter, which agrees with the literature report. ${ }^{44-46}$ Nevertheless, the amount of $\mathrm{Ag}$ associated with DNA was significantly reduced after reacting with $\mathrm{Hg}^{2+}$. The lightexposed sample showed a completely different pattern (Figure 8B). Complexes formed by DNA1 with $\mathrm{Ag}_{1}$ to $\mathrm{Ag}_{7}$ were identified. The relative abundance of the free DNA is decreased. This result also explains that light induced oxidation is reversible since the silver species are still associated with DNA and addition of $\mathrm{NaBH}_{4}$ re-forms AgNCs. In the presence of $\mathrm{Hg}^{2+}$, the overall association between $\mathrm{Ag}$ and DNA is weakened and even disrupted, leading to an irreversible reaction. 


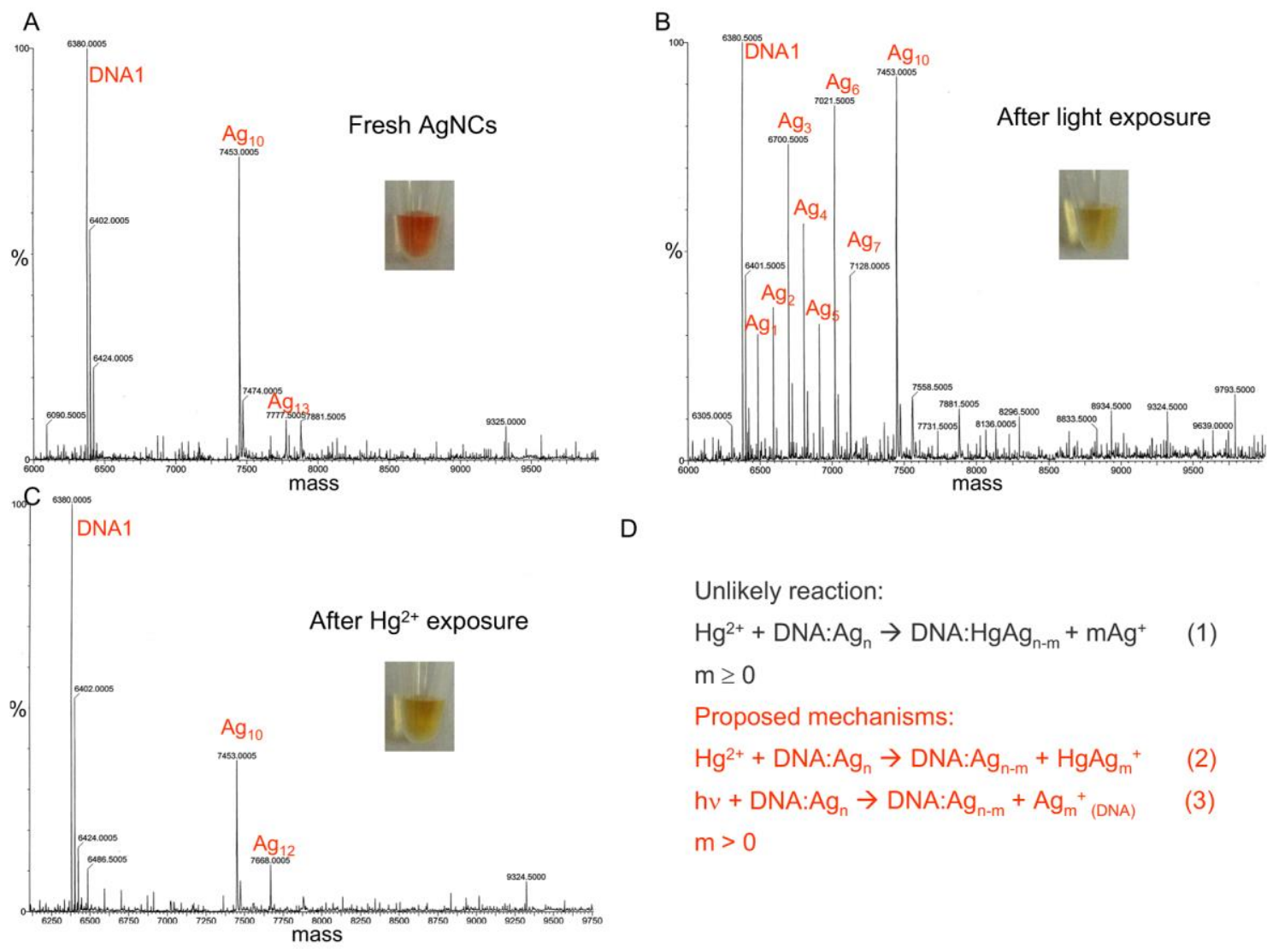

Figure 8. ESI Mass spectrometry characterization of AgNCs templated by DNA1 (A) and its reaction with light (B) or $\mathrm{Hg}^{2+}$ (C). (D) Previously implied reaction mechanism (1); proposed reaction mechanisms with $\mathrm{Hg}^{2+}$ (2) and light (3) in this work.

The commonly proposed reaction mechanism for $\mathrm{Hg}^{2+}$ induced $\mathrm{AgNC}$ quenching can be generalized in $\mathrm{Eq}$ (1) of Figure $8 \mathrm{D}$, where $\mathrm{Hg}^{2+}$ is believed to associate with AgNCs. It may also displace some of the silver in the cluster. However, this mechanism is not supported by our mass spectrometry data. We propose in $\mathrm{Eq}(2)$ that $\mathrm{Hg}^{2+}$ causes the $\mathrm{AgNC}$ to leave the DNA scaffold, or at least the binding is weakened so that dissociation occurred under mass spectrometry conditions. It needs to be pointed out that we do not have evidence that shows whether or how $\mathrm{Hg}^{2+}$ is associated with silver after the reaction. The mechanism of light induced reaction is proposed in $\mathrm{Eq}$ (3), where the 
released silver species are still associated with DNA. To further test our mechanism, EDTA was added to the sample containing $\mathrm{Hg}^{2+}$ and no fluorescence recovery was observed (Figure S4A, ESI). If EDTA was added before $\mathrm{Hg}^{2+}$ addition, then $\mathrm{Hg}^{2+}$ cannot induce fluorescence quenching (Figure S4B), suggesting the high affinity between $\mathrm{Hg}^{2+}$ and EDTA. This experiment also argues against the metallophilic mechanism since $\mathrm{Hg}^{2+}$ might be removed by EDTA in that case.

We reason that the sensitivity to light and $\mathrm{Hg}^{2+}$ correlates with each other because they both related to the ability of this $\mathrm{AgNC}$ to be oxidized. However, the mechanism of each reaction is different. We call the light induced reaction to be oxidation since the fluorescent product can be recovered by adding a reducing agent. It needs to be noted that oxidation does not mean the insertion of oxygen into the AgNC. In fact, such oxygen adducts were not detected. It is more likely to be a number of splitting reactions to reduce the size of the $\mathrm{AgNCs}$, where $\mathrm{Ag}^{+}$are produced and electrons are lost (likely to oxygen) in this process.

Sensitivity to other metal ions. To provide more evidence to link the $\mathrm{Hg}^{2+}$ reaction to the redox property of AgNCs, we examined a number of metal ions with different redox potentials. Similar tests have been previously performed to demonstrate selectivity for $\mathrm{Hg}^{2+}$, where highly oxidative metals such as gold and silver were often omitted. We added $200 \mathrm{nM}$ and $2 \mu \mathrm{M}$ of metal ions (Figure 9) to DNA4 templated AgNCs. $\mathrm{Cu}^{2+}, \mathrm{Ag}^{+}$, and $\mathrm{Au}^{3+}$ also showed significant quenching of the fluorescence spectra (Figure 9A-C). Other lower oxidation potential ions showed little effect (Figure 9D-I). This further supports the redox mechanism of the $\mathrm{Hg}^{2+}$ reaction.

While it may appear odd to use $\mathrm{Hg}^{2+}$ to oxidize $\mathrm{Ag}$ because of its anti-galvanic nature, there are a few examples that noble metal $\mathrm{NCs}$ can be oxidized by metal ions (e.g. $\mathrm{Cu}^{2+}$ and $\mathrm{Pb}^{2+}$ ) whose oxidation power is even weaker than $\mathrm{Hg}^{2+}$. Murray and co-workers reported the oxidation of a $\mathrm{Au}_{25} \mathrm{NC}$ by $\mathrm{Ag}^{+}, \mathrm{Cu}^{2+}$ and $\mathrm{Pb}^{2+}$ using $\mathrm{CH}_{2} \mathrm{Cl}_{2}$ as a solvent. ${ }^{52}$ In that case, it was considered that the redox potential of a nanoparticle or cluster might differ from the bulk metal and that the solvent may also 
influence the potentials. This $\mathrm{Au}_{25} \mathrm{NC}$ has a number of charged states. To rule out that its anionic form that may have a different reducing ability, $\mathrm{Wu}$ studied the neutral $\mathrm{Au}_{25}$ and confirmed its reducing of $\mathrm{Cu}^{2+}$ and $\mathrm{Ag}^{+}$but not $\mathrm{Pb}^{2+}, \mathrm{Fe}^{2+}$ or $\mathrm{Ni}^{2+} .53$ These experiments were again performed in organic solvents. For many $\mathrm{Hg}^{2+}$ sensors based on $\mathrm{AgNCs}, \mathrm{Cu}^{2+}$ is a common interfering ion. All these literature reports are in line with our hypothesis to link $\mathrm{Hg}^{2+}$ with redox reactions. Another method to confirm oxidation is to use X-ray photoelectron spectroscopy (XPS) to measure the oxidation state of silver. However, this requires sample drying. Due to the instability of our sample, significant loss of fluorescence was observed even after drying in vacuum (Figure S5, ESI), preventing us from performing meaningful XPS experiments.

Attributing all metal induced $\mathrm{Au}$ or $\mathrm{AgNC}$ quenching to redox reactions is likely to be oversimplified. Other fluorescence quenching mechanisms may also come into play. Shang and Dong noticed a significant quenching of AgNCs stabilized by poly(methacrylic acid) and they attributed it to the binding of $\mathrm{Cu}^{2+}$ to the polymer. ${ }^{41}$ This was supported by the lack of electronic absorption spectrum change upon $\mathrm{Cu}^{2+}$ addition and the inhibited quenching by adding the free monomer. This quenching was reversed by adding a $\mathrm{Cu}^{2+}$ chelating agent. The energy transfer from $\mathrm{AgNC}$ to the nearby $\mathrm{Cu}^{2+}$ was also proposed to be a possibility. Chang and co-workers synthesized AuNCs capped by a carboxyl ligand and demonstrated fluorescence quenching in the presence of $\mathrm{Pb}^{2+}, \mathrm{Hg}^{2+}$ or $\mathrm{Cd}^{2+} \cdot{ }^{54} \mathrm{It}_{\text {is }}$ likely that quenching was achieved by AuNC aggregation since these metals can be chelated by the surface ligand. Energy transfer to quenchers was another mechanism to achieve quenching. ${ }^{55}$ Wang and co-workers showed the lack of fluorescence lifetime change by $\mathrm{Hg}^{2+}$ induced $\mathrm{AgNC}$ quenching, suggesting disruption of the ground state of $\mathrm{AgNCs}$ by $\mathrm{Hg}^{2+}$, which is consistent with our UV-vis and mass spectrometry measurement. ${ }^{39}$ Ying and co-workers first proposed the direct interaction between $\mathrm{Hg}^{2+}$ and $\mathrm{Au}^{+}$in a protein-stabilized AuNC (i.e. $d^{10}-d^{10}$ metallophilic interaction). ${ }^{37}$ The latter two systems are more directly related to our current study, where we propose that the force driving $\mathrm{Hg}^{2+}$ to interact with AgNCs is from redox reactions. 

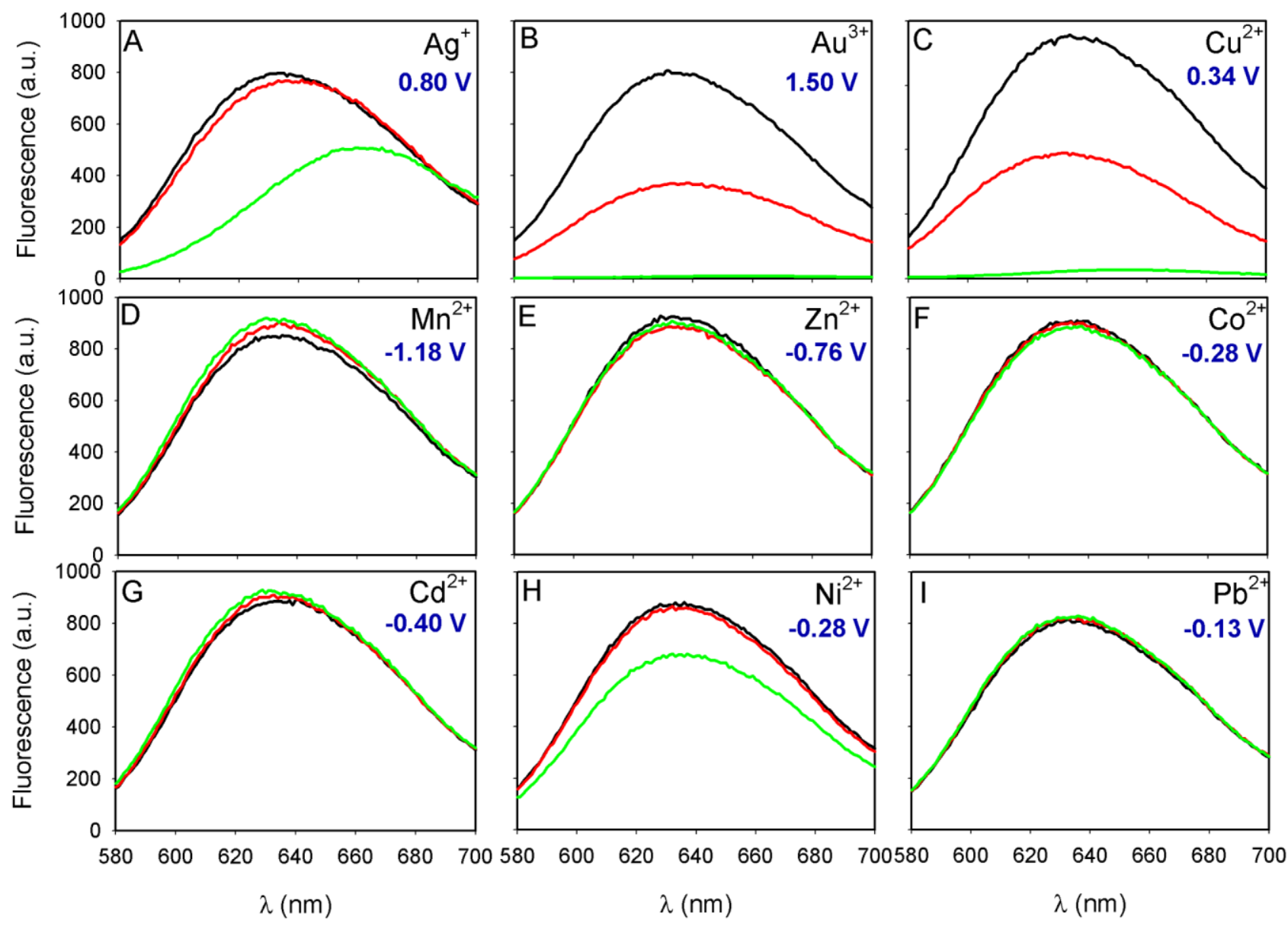

Figure 9. Fluorescence spectra of AgNCs templated by DNA4 (black spectra) and after addition of 200 $\mathrm{nM}$ (red) and $2 \mu \mathrm{M}$ (green) of various metal ions. The redox potentials for the half reaction of turning metal ions to elemental metal are also shown.

\section{Conclusions.}

In summary, based on the previous work that fluorescent AgNCs with different emission properties can be produced using different DNA sequences, we further demonstrated that these AgNCs also have different sensitivity to $\mathrm{Hg}^{2+}$ and to light exposure. In this regard, DNA serves as a tool to allow us to synthetically access various AgNCs. Some AgNCs showed a sharp decrease in fluorescence after exposure to light and $\mathrm{Hg}^{2+}$, while other sequences can effectively protect the associated clusters or even 
enhance fluorescence. A linear relationship between the sensitivity to light exposure and to $\mathrm{Hg}^{2+}$ was identified, suggesting a common origin for AgNCs to respond to these two stimuli. The energy of the light is critical for its photobleaching activity, and shorter wavelengths produce more effective quenching. Photobleaching can be recovered by adding $\mathrm{NaBH}_{4}$, suggesting that the nature of photobleaching is an oxidation reaction. UV-vis spectroscopic studies indicate that the fluorescent AgNCs are converted to other species upon light exposure, while mass spectrometry data indicate that this conversion involves a reduction of the number of silver atoms. On the other hand, $\mathrm{Hg}^{2+}$ weakens the binding between $\mathrm{AgNCs}$ and DNA, and $\mathrm{Hg}^{2+}$ induced quenching cannot be recovered by adding $\mathrm{NaBH}_{4}$. The correlation between light and $\mathrm{Hg}^{2+}$ sensitivity suggests the redox nature of $\mathrm{Hg}^{2+}$ reacting with AgNCs, which is further confirmed by measuring AgNC response to other metal ions with different redox potentials. The overall mechanism is summarized in Figure 1A. In general, AgNCs that can be effectively quenched by $\mathrm{Hg}^{2+}$ are also more easily bleached by light, and the nature of photobleaching is through oxidation. This work unifies many important experimental observations and is important for a better understanding and further development of these NCs for various applications.

\section{Acknowledgments}

We thank the mass spectrometry facility at the University of Waterloo and the assistance of Dr. Richard Smith. Funding for this work is from the University of Waterloo, the Canadian Foundation for Innovation, Early Researcher Award from Ontario Ministry of Research \& Innovation, and the Discovery Grant of the Natural Sciences and Engineering Research Council (NSERC) of Canada.

Electronic supplementary information (ESI) available: Additional photostability, DNA exposure to light, effect of EDTA and AgNC drying. See DOI: 


\section{References:}

1 J. Zheng, P. R. Nicovich and R. M. Dickson, Annu. Rev. Phys. Chem., 2007, 58, 409.

2 J. F. Parker, C. A. Fields-Zinna and R. W. Murray, Acc. Chem. Res., 2010, 43, 1289.

3 R. C. Jin, Nanoscale, 2010, $2,343$.

4 L. Shang, S. J. Dong and G. U. Nienhaus, Nano Today, 2011, 6, 401.

5 B. Y. Han and E. K. Wang, Anal. Bioanal. Chem., 2012, 402, 129.

6 A. Latorre and Á. Somoza, ChemBioChem, 2012, 13, 951.

7 J. Zheng, C. Zhang and R. M. Dickson, Phys. Rev. Lett., 2004, 93, 077402.

8 A. P. Alivisatos, W. Gu and C. Larabell, Annu. Rev. Biomed. Eng., 2005, 7, 55.

9 J. T. Petty, J. Zheng, N. V. Hud and R. M. Dickson, J. Am. Chem. Soc., 2004, 126, 5207.

10 J. P. Xie, Y. G. Zheng and J. Y. Ying, J. Am. Chem. Soc., 2009, 131, 888.

11 T. A. C. Kennedy, J. L. MacLean and J. Liu, Chem. Comm., 2012, 48, 6845.

12 H. Kawasaki, K. Hamaguchi, I. Osaka and R. Arakawa, Adv. Funct. Mater., 2011, 21, 3508.

13 X. Le Guevel, B. Hotzer, G. Jung, K. Hollemeyer, V. Trouillet and M. Schneider, J. Phys. Chem. C, 2011, 115, 10955.

14 L. Maretti, P. S. Billone, Y. Liu and J. C. Scaiano, J. Am. Chem. Soc., 2009, 131, 13972.

15 Y. Cui, Y. Wang, R. Liu, Z. Sun, Y. Wei, Y. Zhao and X. Gao, Acs Nano, 2011, 5, 8684.

16 C. L. Liu, H. T. Wu, Y. H. Hsiao, C. W. Lai, C. W. Shih, Y. K. Peng, K. C. Tang, H. W. Chang, Y. C. Chien, J. K. Hsiao, J. T. Cheng and P. T. Chou, Angew. Chem. Int. Ed., 2011, 50, 7056.

17 M. Zhu, E. Lanni, N. Garg, M. E. Bier and R. Jin, J. Am. Chem. Soc., 2008, 130, 1138.

18 A. Ono, S. Cao, H. Togashi, M. Tashiro, T. Fujimoto, T. Machinami, S. Oda, Y. Miyake, I. Okamoto and Y. Tanaka, Chem. Comm., 2008, 4825.

19 C. I. Richards, S. Choi, J.-C. Hsiang, Y. Antoku, T. Vosch, A. Bongiorno, Y.-L. Tzeng and R. M. Dickson, J. Am. Chem. Soc., 2008, 130, 5038.

20 G. Y. Lan, W. Y. Chen and H. T. Chang, RSC Advances, 2011, 1, 802. 
21 E. G. Gwinn, P. O'Neill, A. J. Guerrero, D. Bouwmeester and D. K. Fygenson, Adv. Mater., 2008, 20, 279.

22 J. Sharma, H.-C. Yeh, H. Yoo, J. H. Werner and J. S. Martinez, Chem. Comm., 2010, 46, 3280.

23 M. L. Neidig, J. Sharma, H.-C. Yeh, J. S. Martinez, S. D. Conradson and A. P. Shreve, J. Am. Chem. Soc., 2011, 133, 11837.

24 W. W. Guo, J. P. Yuan, Q. Z. Dong and E. K. Wang, J. Am. Chem. Soc., 2010, 132, 932.

25 H. C. Yeh, J. Sharma, J. J. Han, J. S. Martinez and J. H. Werner, Nano Lett., 2010, 10, 3106.

26 H.-C. Yeh, J. Sharma, I.-M. Shih, D. M. Vu, J. S. Martinez and J. H. Werner, J. Am. Chem. Soc., 2012, 134, 11550.

27 J. Li, X. Zhong, H. Zhang, X. C. Le and J.-J. Zhu, Anal. Chem., 2012, 84, 5170.

28 J. J. Yin, X. X. He, K. M. Wang, Z. H. Qing, X. Wu, H. Shi and X. H. Yang, Nanoscale, 2012, 4, 110 .

29 W. W. Guo, J. P. Yuan and E. K. Wang, Chem. Comm., 2011, 47, 10930.

30 Z. Q. Yuan, M. H. Peng, Y. He and E. S. Yeung, Chem. Comm., 2011, 47, 11981.

31 Z. Zhou, Y. Du and S. Dong, Biosens. Bioelectron., 2011, 28, 33.

32 C. C. Huang, C. K. Chiang, Z. H. Lin, K. H. Lee and H. T. Chang, Anal. Chem., 2008, 80, 1497.

33 T. Li, L. B. Zhang, J. Ai, S. J. Dong and E. K. Wang, ACS Nano, 2011, 5, 6334.

34 J. T. Petty, B. Sengupta, S. P. Story and N. N. Degtyareva, Anal. Chem., 2011, 83, 5957.

35 X. Jia, J. Li, L. Han, J. Ren, X. Yang and E. Wang, Acs Nano, 2012, 6, 3311.

36 Y. Tao, Y. Lin, Z. Huang, J. Ren and X. Qu, Analyst, 2012, 137, 2588.

37 J. Xie, Y. Zheng and J. Y. Ying, Chem. Comm., 2010, 46, 961.

38 C. L. Guo and J. Irudayaraj, Anal. Chem., 2011, 83, 2883.

39 W. W. Guo, J. P. Yuan and E. K. Wang, Chem. Comm., 2009, 3395.

40 G. Y. Lan, C. C. Huang and H. T. Chang, Chem. Comm., 2010, 46, 1257.

41 L. Shang and S. J. Dong, J. Mater. Chem., 2008, 18, 4636. 
43 P. Pyykko, Chem. Rev., 1997, 97, 597.

44 C. M. Ritchie, K. R. Johnsen, J. R. Kiser, Y. Antoku, R. M. Dickson and J. T. Petty, J. Phys. Chem. C, 2007, 111, 175.

45 P. R. O'Neill, L. R. Velazquez, D. G. Dunn, E. G. Gwinn and D. K. Fygenson, J. Phys. Chem. C, 2009, 113, 4229.

46 T. Driehorst, P. O'Neill, P. M. Goodwin, S. Pennathur and D. K. Fygenson, Langmuir, 2011, 27, 8923.

47 B. Sengupta, C. M. Ritchie, J. G. Buckman, K. R. Johnsen, P. M. Goodwin and J. T. Petty, J. Phys. Chem. C, 2008, 112, 18776.

48 J. Sharma, R. C. Rocha, M. L. Phipps, H.-C. Yeh, K. A. Balatsky, D. M. Vu, A. P. Shreve, J. H. Werner and J. S. Martinez, Nanoscale, 2012, 4, 4107.

49 S. Choi, J. Yu, S. A. Patel, Y.-L. Tzeng and R. M. Dickson, Photoch. Photobio. Sci., 2011, 10, 109.

50 P. R. O'Neill, E. G. Gwinn and D. K. Fygenson, J. Phys. Chem. C, 2011, 115, 24061.

51 X. S. Zhang, B. S. Rosenstein, Y. Wang, M. Lebwohl and H. C. Wei, Free Radical Bio. Med., 1997, 23, 980.

52 J.-P. Choi, C. A. Fields-Zinna, R. L. Stiles, R. Balasubramanian, A. D. Douglas, M. C. Crowe and R. W. Murray, J. Phys. Chem. C, 2010, 114, 15890.

53 Z. Wu, Angew. Chem., Int. Ed., 2012, 51, 2934.

54 C. C. Huang, Z. Yang, K. H. Lee and H. T. Chang, Angew. Chem. Int. Ed., 2007, 46, 6824.

55 C.-W. Chen, C.-H. Wang, C.-M. Wei, C.-Y. Hsieh, Y.-T. Chen, Y.-F. Chen, C.-W. Lai, C.-L. Liu, C.-C. Hsieh and P.-T. Chou, J. Phys. Chem. C, 2009, 114, 799. 